\title{
Asymmetric Ketone Reduction using Chiral Oxazaborolidines derived from Aziridine Carbinols
}

\author{
Johannes G.H. Willems, F. Jan Dommerholt, Jeannet B. Hammink, Ariëla M. Vaarhorst, \\ Lambertus Thijs and Binne Zwanenburg*
}

\begin{abstract}
Department of Organic Chemistry, NSR Center for Molecular Structure, Design and Synthesis, University of Nijmegen, Toernooiveld, 6525 ED Nijmegen, The Netherlands
\end{abstract}

\begin{abstract}
Asymmetric borane reduction of acetophenone using 1,3,2-oxazaborolidines derived from aziridine-2-tertiairy alcohols 1 and 2 yielded the corresponding alcohol in high optical yields. The synthesis of the novel chiral catalysts 1 and 2 using D-and L-serine, and D-and L-threonine as starting material is described.
\end{abstract}

The development of catalytic methodology is an active field of research in organic chemistry. For the enantioselective reduction of prochiral ketones, one of the more successful reactions is based on the use of 1,3,2oxazaborolidines as chiral inductor in the reduction process. Chiral 1,3,2-oxazaborolidines are generated from chiral 1,2-aminoalcohols and borane as was first reported by Itsuno et al. ${ }^{1}$ Corey et al. ${ }^{2}$ soon thereafter prepared an oxazaborolidine derived from $\alpha, \alpha$-diphenyl-2-pyrrolidinemethanol (4) which was employed in the reduction of prochiral ketones with borane ( $\mathrm{BH}_{3}$ - THF, CBS-method).

Several other chiral 1,3,2-oxazaborolidines have been reported; recently two reviews about the development and application of chiral oxazaborolidines have appeared ${ }^{3}$. Cyclic aminoalcohols, namely azetidine ${ }^{4}$, pyrrolidine ${ }^{5}$ and piperidine ${ }^{6}$ derived carbinols 3,4 and 5 , respectively, have been studied extensively, as basis for 1,3,2-oxazaborolidine catalysts.

Our interest in chiral small-ring heterocycles, especially functionalized epoxides ${ }^{7}$ and aziridines ${ }^{8}$, led us to investigate the aziridine-2-alcohols 1 and $\mathbf{2}$ as precatalyst systems. Comparison of the asymmetric reductions with the oxazaborolidine catalysts derived from the corresponding 6,5,4 and 3-membered cyclic aminoalcohols is clearly of interest. The reaction of choice for this comparison is reduction of prochiral ketones employing such oxazaborolidines.
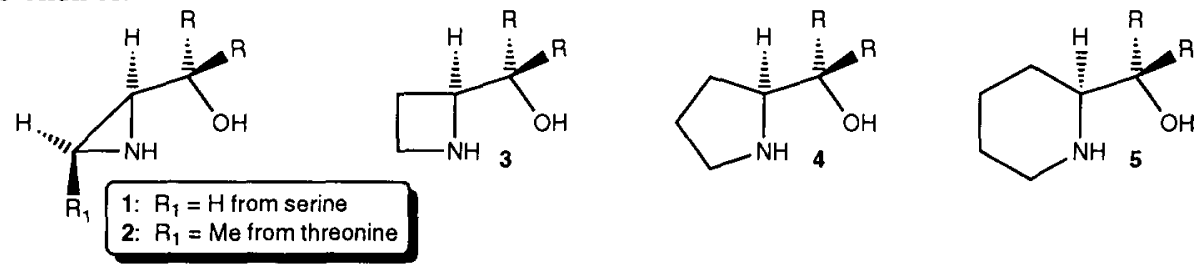

Several approaches to the preparation of optically active aziridine-2-carboxylic esters, the precursors of the aziridine-2-tertiairy alcohols 1 and 2 , are known in the literature ${ }^{9}$. We developed ${ }^{10}$ an improved procedure for the synthesis of enantiopure $\mathrm{N}$-trityl-aziridine-2-carboxylic esters from serine and threonine. The $\mathrm{N}$-tritylaziridine-2-carboxylic esters were converted into the corresponding $\mathrm{N}$-trityl-aziridine-2-carbinols using phenylmagnesium bromide, followed by detritylation with sulphuric acid in methanol/THF yielding enantiopure aziridine-2-tertiairy alcohols in good yields ${ }^{11}(80 \%)$ (Scheme 1 ).

The thus-prepared aziridine-2-carbinols $1 \mathbf{a}$ and $\mathbf{1 b}$ (L-and D-serine derived precatalysts) were converted into the corresponding oxazaborolidines $8 \mathbf{a}$ and $\mathbf{8 b}$ by an 'in situ' reaction with an excess of borane- $\mathrm{Me}_{2} \mathrm{~S}$ complex in THF at reflux temperature for $15 \mathrm{hrs}$, followed by removal of the solvent and excess borane in 
vacuo. The procedure for the reduction of acetophenone involves a fast addition of the ketone to a THF solution of the catalyst- $\mathrm{BH}_{3}-\mathrm{Me}_{2} \mathrm{~S}$ complex at room temperature. This operation caused a raise of the temperature of the reaction mixture to $\mathrm{ca} 45^{\circ} \mathrm{C}$. The progress of the reaction was monitored by TLC. In most cases acetophenone (6) was converted into phenylethyl alcohol (7) within $5 \mathrm{~min}$. in high chemical yields.

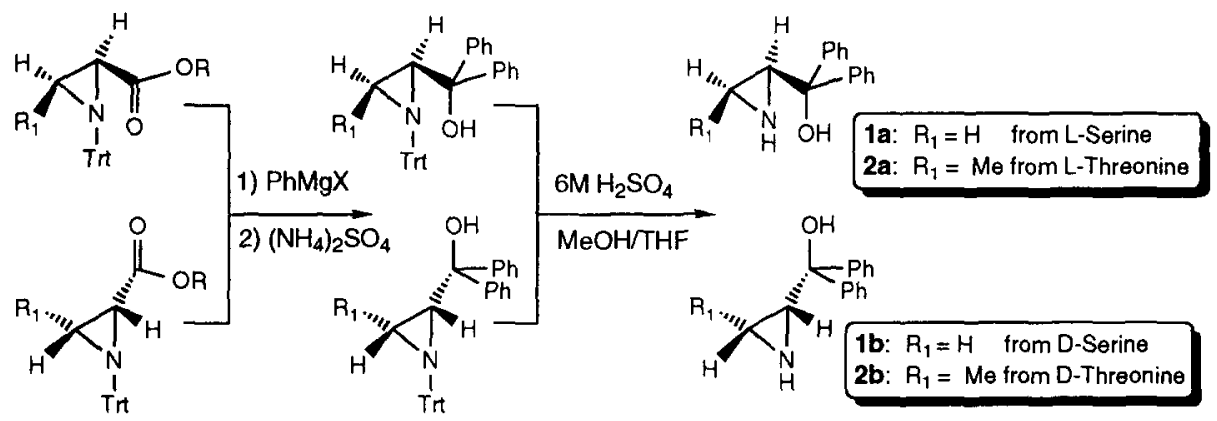

Scheme I

In the case of precatalysts $\mathbf{2 a}$ and $\mathbf{2 b}$ (derived from L-and D-threonine) the oxazaborolidines $\mathbf{9 a}$ and $\mathbf{9 b}$ were prepared in toluene at room temperature in $10 \mathrm{~min}$. The enantiomeric purity of alcohol 7 was determined by GLC using the camphanoyl derivative of 7 , and by HPLC using a chiral column (Daicel Chiralcel OD). Both methods gave identical results. The absolute configuration of the alcohol was deduced from measurement of its optical rotation. Commercially available (S)-2- $\alpha, \alpha$-diphenyl-2-pyrrolidinemethanol (4) was used for comparison under the same conditions as described above. The results of the ketone reduction are collected in the table. It was found that various factors, such as the oxazaborolidine preparation procedure, the molar ratio of chiral aminoalcohol and borane during the preparation of the catalyst, and the solvent used had a profound effect on the success of the asymmetric ketone reduction. For precatalysts 1a and 1b high stereoselectivity was always attained with the reagent prepared from a 1:3 or 1:6 molar ratio of the aminoalcohol and borane, whereas the reduction with the catalyst obtained from 1:1 molar ratio of aminoalcohol and borane resulted in a disappointingly low selectivity.

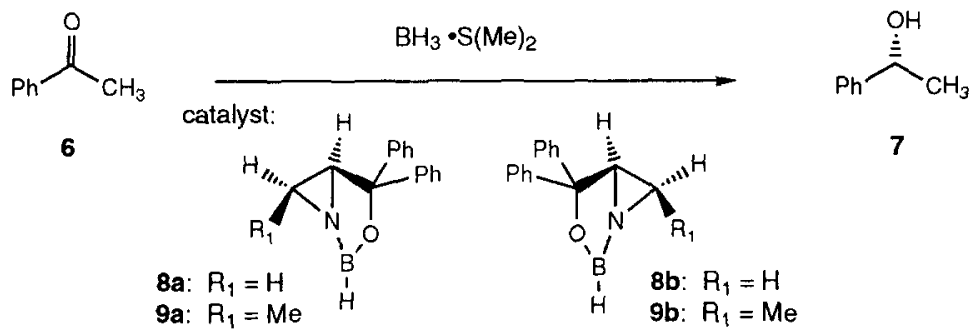

Scheme 2

It turned out to be essential that during the preparation of oxazaborolidines $\mathbf{8 a}$ and $\mathbf{8 b}$ the precatalysts $1 \mathbf{a}$ and $1 \mathrm{~b}$ were refluxed in $\mathrm{THF}^{12}$ with 6 equiv. of $\mathrm{BH}_{3}-\mathrm{SMe}_{2}$ for $15 \mathrm{hrs}$. When a lower temperature was used during the 'in-situ' oxazaborolidine preparation $(50 \circ \mathrm{C})$ the enantioselectivity of the reduction reaction was decreased. However, in the case of the preparation of oxazaborolidines $9 \mathbf{a}$ and $\mathbf{9 b}$ optimum results were obtained when the precatalysts $\mathbf{2 a}$ and $\mathbf{2 b}$ and 2 equiv. of $\mathrm{BH}_{3}$-THF were mixed in toluene at room temperature for $10 \mathrm{~min}$, immediately followed by the reduction using $\mathrm{BH}_{3}-\mathrm{SMe}_{2}$ in toluene. The optimum reaction conditions described for $\mathbf{1 a}$ and $\mathbf{1 b}$ gave only moderate ee-values (30\%) when applied for $\mathbf{2 a}$ and $\mathbf{2 b}$. When the optimum reaction conditions for the preparation of oxazaborolidines $9 \mathbf{a}$ and $9 \mathrm{~b}$ were used for $8 \mathbf{a}$ and $8 \mathbf{b}$ the enantiomeric purity of alcohol 7 was relatively low $(53 \%)$. 
These findings indicate that the cis methyl-group in the oxazaborolidines $9 \mathrm{a}$ and $9 \mathrm{~b}$, when compared with the catalysts $8 \mathbf{a}$ and $\mathbf{8 b}$, has an enormous effect on the asymmetric induction capability of the chiral catalyst in the reduction of acetophenone. Hitherto we were not able to isolate the oxazaborolidines 8 and $\mathbf{9}$ in pure form. In order to characterize the oxazaborolidine catalysts, the synthesis of stable oxazaborolidines derived from aziridine-2-tertiairy alcohols and alkylboronates ${ }^{13}$ is currently investigated.

Table. Asymmetric Reduction of Acetophenone with Oxazaborolidines derived from 1, 2 and 4

\begin{tabular}{|c|c|c|c|c|}
\hline Entry & Aminoalcohol & Solvent & e.e $(\%)$ & $\begin{array}{c}\text { Absolute } \\
\text { config. }\end{array}$ \\
\hline 1 & $(S)-(\mathbf{1 a})^{\mathbf{a}}$ & THF & 94 & $\mathrm{R}$ \\
\hline 2 & $(S)-(1 a)^{b}$ & Toluene & 53 & $\mathbf{R}$ \\
\hline 3 & $(\mathrm{R})-(1 \mathrm{~b})^{\mathrm{a}}$ & THF & 92 & $S$ \\
\hline 4 & $(S)-(2 a)^{a}$ & THF & 30 & $\mathbf{R}$ \\
\hline 5 & $(S)-(2 a)^{b}$ & Toluene & 94 & $\mathbf{R}$ \\
\hline 6 & $(R)-(2 b)^{b}$ & Toluene & 93 & $S$ \\
\hline 7 & $(S)-(4)^{\mathrm{a}}$ & THF & 92 & $\mathbf{R}$ \\
\hline 8 & $(S)-(4)^{b}$ & Toluene & 90 & $\mathrm{R}$ \\
\hline
\end{tabular}

a) Catalyst preparation using $\mathrm{BH}_{3}$-DMS (6 equiv.) for $15 \mathrm{~h}$. at reflux temperature in THF.

b) Catalyst preparation using $\mathrm{BH}_{3}$ - THF ( 2 equiv.) for $10 \mathrm{~min}$. at room temperature in toluene.

In conclusion, the synthesis of a new class of chiral precatalysts, aziridine-2-carbinols $\mathbf{1}$ and $\mathbf{2}$, which can conveniently be converted into the corresponding oxazaborolidines, is described. These new catalysts are attractive because of their readily availability in both enantiomeric forms, starting from L-and D-serine and L-and D-threonine, respectively. The enantioselective reduction of acetophenone using precatalysts 1,2 , and 4 took place with high ee-values ( $>90 \%$ ). The results with the three-membered ring catalysts 8 and 9 from aziridinediphenylcarbinols gave similar ee-values as the five membered L-proline (4) derived catalyst.

\section{Experimental}

Typical procedure for acetophenone reduction using $10 \% 1 a$ as the catalyst: The reactions were run under an argon atmosphere in a flame dried 3-necked reaction flask equipped with a magnetic stirrer and a thermometer. To a solution of $1 \mathrm{a}(56 \mathrm{mg}, 0.25 \mathrm{mmol})$ in THF $(10 \mathrm{~mL})$ a BH $3-\mathrm{Me}_{2} \mathrm{~S}$ solution in THF $(750 \mu \mathrm{L}, 2 \mathrm{M}, 1.5 \mathrm{mmol})$ was added. This solution was heated at reflux temperature for $15 \mathrm{~h}$, followed by removal of the solvent and excess $\mathrm{BH}_{3}-\mathrm{Me}_{2} \mathrm{~S}$ in vacuo. THF $(3.5 \mathrm{~mL})$ was added to the white solid catalyst, followed by $\mathrm{BH}_{3}-\mathrm{SMe}_{2}$ in THF (1.25 mL, 2M, $2.5 \mathrm{mmol})$ and the immediate addition of acetophenone $(292 \mu \mathrm{L}, 2.5 \mathrm{mmol})$. An exothermic reaction took place. After $15 \mathrm{~min}$ all acetophenone had been consumed (TLC) and the reaction was quenched with $\mathrm{MeOH}(1.25 \mathrm{~mL})$. Dilute sulphuric acid $(4 \mathrm{ml}, 1 \mathrm{M})$ was added, followed by the removal of the organic solvents in vacuo. The aqueous residue was extracted with ether $(3 x)$, washed with a saturated bicarbonate solution, dried over $\mathrm{MgSO}_{4}$ and concentrated to give (R)-(-)-phenylethyl alcohol in $90 \%$ chemical yield with a purity of $96 \%$ by GLC. The enantiomeric purity of this product was $94 \%$ as was determined by GLC (camphanoyl derivative) and HPLC (Daicel Chiralcel OD).

Typical procedure for acetophenone reduction using $5 \% 2 a$ as the catalyst: The reactions were run under a nitrogen atmosphere in a flame dried 3-necked reaction flask equipped with a magnetic stirrer. To a solution of

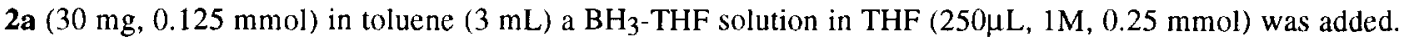
The solution was stirred at room temperature for $10 \mathrm{~min}$. After the addition of acetophenone ( $292 \mu \mathrm{L}, 2.5 \mathrm{mmol}$ ) a $\mathrm{BH}_{3}-\mathrm{SMe}_{2}$ solution in toluene $(1.25 \mathrm{~mL}, 2 \mathrm{M}, 2.5 \mathrm{mmol})$ was added immediately. An exothermic reaction took place. After $30 \mathrm{~min}$, all acetophenone had been consumed (TLC). The reaction was quenched with MeOH $(1.25 \mathrm{~mL})$, extracted with dilute sulphuric acid $(4 \mathrm{ml}, 1 \mathrm{M})$, followed by a washing with a saturated sodium bicarbonate solution. The organic layer was dried over $\mathrm{MgSO}_{4}$ and concentrated in vacuo to give $(\mathrm{R})-(-)-$ phenylethyl alcohol in a yield of $90 \%$ with a purity of $96 \%$ by GLC. The enantiomeric purity of this product was $94 \%$ as determined by GLC (camphanoyl derivative) and HPLC (Daicel Chiralcel OD). 
Acknowledgement. We are grateful to DSM Research for their financial support.

\section{References and notes}

1. (a) Itsuno, S.; Sakurai, Y.; Ito, K.; Hirao, A.; Nakahama, S.; Bull. Chem. Soc. Jpn., 1987, 60, 395, and references therein. (b) Itsuno, S.; Nakano, M.; Miyazaki, K.; Masuda, H.; Itoh, K.; Hirao, A.; Nakahama, S.; J. Chem. Soc., Perkin Trans. 1, 1985, 2039. In this paper, a defined structure of the reagent was not reported, but the structure became apparent after Corey's work (ref 2).

2. Corey, E.J.; Bakshi, R.K.; Shibata, S.; J. Am. Chem. Soc., 1987, 109, 5551.

3. For recent reviews, see: (a) Deloux, L.; Srebnik, M.; Chem. Rev., 1993, 93, 763 (b) Martens, J.; Wallbaum, S.; Tetrahedron Asymmetry, 1992, 3, 1475.

4. (a) Behnen, W.; Dauelsberg, Ch.; Wallbaum, S.; Martens, J.; Synth. Commun., 1992, 22, 2143. (b) Rao, A.V.R.; Gurjar, M.K.; Kaiwar, V.; Tetrahedron Asymmetry, 1992, 3, 859.

5. (a) Cai, D.; Tschaen, D.; Shi, Y-J.; Verhoeven, T.R.; Reamer, R.A.; Douglas, A.W.; Tetrahedron Lett., 1993, 34, 3243. (b) Shinkai, I.; J. Heterocyclic Chem., 1992, 29, 627. c) Cai, D.; Tschaen, D.; Shi, YJ.; Verhoeven, T.R.; Reamer, R.A.; Douglas, A.W.; Tetrahedron Lett., 1993, 34, 3243.

6. Rao, A.V.R.; Gurjar, M.K.; Sharma, P.A.; Kaiwar, V.; Tetrahedron Lett., 1990, 31, 2341.

7. (a) Lemmens, J.M.; Blommerde, W.W.J.M.; Thijs, L.; Zwanenburg, B.; J. Org. Chem., 1984, 49, 2231. (b) Thijs, L.; Dommerholt, F.J.; Leemhuis, F.M.C.; Zwanenburg, B.; Tetrahedron Lett., 1990, 3I, 6589. (c) Leemhuis, F.M.C.; Thijs, L.; Zwanenburg, B.; J. Org. Chem., 1993, 58, 7172.

8. (a) Legters, J.; Thijs, L.; Zwanenburg, B.; Tetrahedron Lett., 1989, 30, 4881. (b) Thijs, L.; Porskamp, J.J.M.; van Loon, A.A.W.M.; Derks, M.P.W.; Feenstra, R.W.; Legters, J.; Zwanenburg, B.; Tetrahedron, 1990, 46, 2611. (c) Legters, J.; Thijs, L.; Zwanenburg, B.; Tetrahedron, 1991, 47, 5287. (d) Legters, J.; Thijs, L.; Zwanenburg, B.; Recl. Trav. Chim. Pays-Bas, 1992, 111, 16. (e) Legters, J.; Willems, J.G.H.; Thijs, L.; Zwanenburg, B.; Recl. Trav. Chim. Pays-Bas, 1992, 111, 59. (f) Legters, J.; Thijs, L.; Zwanenburg, B.; Recl. Trav. Chim. Pays-Bas, 1992, 111, 75. (g) Legters, J.; Thijs, L.; Zwanenburg, B.; Recl. Trav. Chim. Pays-Bas, 1992, $111,211$.

9. (a) For a recent review, see: Tanner, D.; Angew. Chem., 1994, 106, 625. (b) Legters, J.; Thijs, L.; Zwanenburg, B.; Tetrahedron Lett., 1989, 30, 4881. (c) Legters, J.; Thijs, L.; Zwanenburg, B.; Tetrahedron, 1991, 47, 5287.

10. The $N$-trityl methyl esters of $L$ and $D$-serine and $L$ and $D$-threonine, respectively, give upon treatment with methanesulfonyl chloride and triethylamine in refluxing THF the corresponding enantiopure $\mathrm{N}$-trityl aziridine-2-carboxylic esters in quantitative yields. Details will be published in due time. For similar preparations, see: (a) Nakajima, K.; Takai, F.; Tanaka, T.; Okawa, K.; Bull. Chem. Soc. Jpn., 1978, 51, 1577. (b) Nakajima, K.; Takai, F.; Tanaka, T.; Okawa, K.; Biopolymers, 1981, 20, 1811. (c) Wakamiya, T.; Shimbo, K.; Shiba, T.; Nakajima, K.; Neya, M.; Okawa, K.; Bull. Chem. Soc. Jpn., $1982,55,3878$.

11. After recrystallization the enantiomeric purity of the aziridine-2-tertiairy alcohols was determined by 400 MHz NMR using camphanoyl chloride as a chiral derivatizing agent and by HPLC (DAICEL Chiralcel OD) (hexane/isopropanol $=95: 5$ ).

12. During the preparation of the oxazaborolidine derived from precatalyst $1 \mathrm{a}$, it was found that some reductive cleavage of the $\beta-\mathrm{C}-\mathrm{N}$ bond of the aziridine ring took place, yielding the oxazaborolidine derived from (S)-2-amino-1,1-diphenylpropanol.After hydrolysis this aminoalcohol was isolated.

13. Corey, E.J.; Link, J.O.; Tetrahedron Lett., 1992, 33, 4141. 